\title{
REVIEW
}

\section{Allogeneic hematopoietic cell transplantation in patients with AML not achieving remission: potentially curative therapy}

\author{
B Gyurkocza ${ }^{1,2}$, HM Lazarus $^{3}$ and S Giralt ${ }^{1,2}$
}

Patients with acute myeloid leukemia (AML) who fail to achieve complete remission (CR) have a dismal prognosis. Although data suggest that durable remissions can be achieved in approximately $30 \%$ of patients with refractory or relapsed AML after allogeneic hematopoietic cell transplantation (HCT), only a small fraction of those patients are offered this therapeutic option. Importantly, patients with primary refractory AML have distinctly better outcomes following allogeneic HCT than those with refractory relapse. Access to suitable donors could be one of the main barriers in these situations. However, with recent developments in the field of allogeneic HCT, such as alternative donor sources, high-resolution HLA-typing, reduced intensity conditioning regimens and improvements in supportive care, this approach has the potential to offer long-term survival for patients with refractory and relapsed AML and should be considered as early after diagnosis as possible. Incorporating novel agents into the conditioning regimen or as post-transplant maintenance therapy could further improve outcomes and render older or medically infirm patients with refractory or relapsed AML eligible for allogeneic HCT. In this review, we summarize existing data on allogeneic HCT in patients with refractory or relapsed $A M L$ and explore novel approaches with the potential to improve outcomes in this patient population.

Bone Marrow Transplantation (2017) 52, 1083-1090; doi:10.1038/bmt.2017.8; published online 27 February 2017

\section{INTRODUCTION}

Complete remission (CR), as defined by the International Working Group, ${ }^{1}$ can be achieved with infusional cytarabine and an anthracycline in approximately $60-70 \%$ of acute myeloid leukemia (AML) patients aged $<60$ years. $^{2}$ The $C R$ rate, however, drops to about $40-50 \%$ in older AML patients (deemed sufficiently functional to undergo induction therapy) with similar induction therapies of standard-dose cytarabine and an anthracycline. ${ }^{3-5}$ According to current practice and National Comprehensive Cancer Network (NCCN) guidelines, allogeneic hematopoietic cell transplantation (HCT) should be offered to patients who achieve CR but are at high risk for relapse, based on various genetic, molecular or clinical risk factors. ${ }^{6,7}$

Patients, who relapse after initial remission, in general, may achieve a second CR in $30-45 \%$ of the time when using a more aggressive reinduction regimen ${ }^{8-14}$; this rate can be as low as $10-15 \%$ in patients whose first CR lasted for $<1$ year. $^{15}$

Patients with primary induction or reinduction failure have poor prognosis with minimal, if any chance of cure using alternative chemotherapy or early-phase clinical trials testing investigational agents. However, several, mostly retrospective studies have shown that long-term survival is possible in selected patients who undergo allogeneic HCT using an HLA-matched sibling donor. ${ }^{16,17}$ Table 1 summarizes recent reports on transplant outcome in AML patients with primary induction failure or in relapse. Because of the time and logistics required to perform an unrelated donor search, there is less experience with HCT from unrelated donors in this scenario; but the limited data available demonstrate that cure is possible in a similar proportion of patients. ${ }^{18}$ Furthermore, there are emerging data showing that allogeneic HCT using alternative donor graft sources, such as HLA-haploidentical donors or umbilical cord blood, also could result in long-term disease control and survival in selected patients who have refractory or relapsed AML. These retrospective data emphasize the importance of HLA-typing patients and family members shortly after the diagnosis of AML so that valuable time is not lost in identifying suitable donors should remission induction attempts fail. Herein we review the data and provide recommendations for AML patients who have primary refractory or relapsed disease.

\section{PRIMARY INDUCTION FAILURE}

The traditional definition of primary induction failure in patients with $A M L$ is the failure to achieve $C R$ after one or two cycles of induction therapy. ${ }^{19}$ As above, approximately $30-40 \%$ of AML patients younger than 60 years and about $50-60 \%$ of older AML patients fail to achieve CR with infusional cytarabine and an anthracycline or similarly aggressive induction therapy. ${ }^{2-5}$ Per current NCCN guidelines for AML, ${ }^{7}$ patients initially treated with high-dose cytarabine and who have significant residual disease 7-10 days after completion of induction chemotherapy also should be considered to have experienced induction failure.

In a retrospective analysis of European Group for Blood and Marrow Transplantation (EBMT) data, Nagler et al. ${ }^{18}$ reported on 852 AML patients with primary induction failure or refractory relapse who underwent allogeneic HCT. The high-dose conditioning used was cyclophosphamide and either high-dose busulfan or high-dose total body irradiation (TBI) - based regimens. $^{18}$ Not surprisingly, in this retrospective data set, the majority of patients $(n=565 ; 66.7 \%)$ received allografts from

\footnotetext{
${ }^{1}$ Memorial Sloan Kettering Cancer Center, New York, NY, USA; ${ }^{2}$ Weill Cornell Medical College of Cornell University, New York, NY, USA and ${ }^{3}$ University Hospitals Cleveland Medical Center, Case Comprehensive Cancer Center, Cleveland, OH, USA. Correspondence: Dr B Gyurkocza, Adult BMT Service, Memorial Sloan Kettering Cancer Center, 1275 York Avenue, New York, NY 10065, USA.

E-mail: gyurkocb@mskcc.org

Received 28 September 2016; revised 29 November 2016; accepted 3 January 2017; published online 27 February 2017
} 
Table 1. Summary of retrospective data on allogeneic $\mathrm{HCT}$ in patients with refractory or relapsed AML

\begin{tabular}{|c|c|c|c|c|c|c|c|}
\hline Study & Year & $\begin{array}{l}\text { Number of } \\
\text { patients }\end{array}$ & AML stage & Donor type & Conditioning & $\begin{array}{l}\% \text { OS } \\
\text { (at years) }\end{array}$ & $\begin{array}{l}\% \text { DFS } \\
\text { (at years) }\end{array}$ \\
\hline Appelbaum & 1983 & 17 & Untreated relapse & HLA-matched siblings & High-dose, TBI based & $29(2-6)$ & \\
\hline et al. ${ }^{33}$ & & 20 & Refractory relapse & & & $10(2$ & \\
\hline Biggs et al. ${ }^{16}$ & 1992 & $\begin{array}{r}120 \\
88\end{array}$ & $\begin{array}{l}\text { Untreated relapse } \\
\text { Refractory relapse }\end{array}$ & $\begin{array}{l}\text { HLA-matched sibilngs } \\
\text { HLA-matched siblings }\end{array}$ & $\begin{array}{l}\text { High-dose, TBI or } \\
\text { chemotherapy based }\end{array}$ & & $\begin{array}{l}23(5) \\
21(3)\end{array}$ \\
\hline Brown et al. ${ }^{31}$ & 1995 & 40 & Untreated relapse & HLA-matched siblings & High-dose, TBI based & & $29(4)$ \\
\hline Sierra et al. ${ }^{34}$ & 2000 & $\begin{array}{l}81 \\
16\end{array}$ & $\begin{array}{l}\text { Relapse } \\
\text { Primary refractory }\end{array}$ & Unrelated donors & High-dose TBI based & & $\begin{array}{l}7(5) \\
19(5)\end{array}$ \\
\hline Burke et al. ${ }^{48}$ & 2003 & 16 & $\begin{array}{l}\text { Relapse and primary induction } \\
\text { failure }\end{array}$ & Related & $\begin{array}{l}\text { Radiolabeled anti-CD33 Ab and } \\
\text { high-dose chemotherapy }\end{array}$ & & $18(5)$ \\
\hline Fung et al. ${ }^{17}$ & 2003 & 68 & Primary refractory & $\begin{array}{l}\text { HLA-matched related } \\
\text { and unrelated }\end{array}$ & $\begin{array}{l}\text { High-dose TBI or } \\
\text { chemotherapy based }\end{array}$ & $30(3)$ & $31(3)$ \\
\hline Wong et al. $^{35}$ & 2005 & 103 & $\begin{array}{l}\text { Primary refractory } \\
\text { Refractory relapse }\end{array}$ & Related and unrelated & High-dose and RIC & $\begin{array}{l}29(2) \\
19(2)\end{array}$ & $\begin{array}{l}26(2) \\
17(2)\end{array}$ \\
\hline Schmid et al. ${ }^{23}$ & 2006 & 103 & $\begin{array}{l}\text { Primary induction failure, } \\
\text { untreated and refractory } \\
\text { relapse }\end{array}$ & Related and unrelated & FLAMSA followed by RIC & $32(4)$ & $30(4)$ \\
\hline Duval et al. ${ }^{36}$ & 2010 & 1673 & $\begin{array}{l}\text { Primary induction failure, } \\
\text { untreated and refractory } \\
\text { relapse }\end{array}$ & Related and unrelated & $\begin{array}{l}\text { High-dose TBI- or } \\
\text { chemotherapy-based }\end{array}$ & $19(3)$ & \\
\hline $\begin{array}{l}\text { Craddock } \\
\text { et al. } .^{20}\end{array}$ & 2011 & 168 & Primary induction failure & Unrelated & High-dose and RIC & $22(5)$ & \\
\hline $\begin{array}{l}\text { Schneidawind } \\
\text { et al. }\end{array}$ & 2013 & 62 & $\begin{array}{l}\text { Primary induction failure and } \\
\text { relapse }\end{array}$ & Related and unrelated & FLAMSA followed by RIC & $39(2)$ & $26(2)$ \\
\hline $\begin{array}{l}\text { Jabbour } \\
\text { et al. }\end{array}$ & 2014 & 28 & Primary induction failure & $\begin{array}{l}\text { Related, unrelated, HLA- } \\
\text { haploidentical related }\end{array}$ & Various & $39(3)$ & \\
\hline Nagler et al. ${ }^{18}$ & 2015 & 852 & Refractory & Related and unrelated & $\begin{array}{l}\text { High-dose BU based } \\
\text { High-dose TBI based }\end{array}$ & $\begin{array}{l}31(2) \\
33(2)\end{array}$ & $\begin{array}{l}25(2) \\
28(2)\end{array}$ \\
\hline Jaiswal et al. ${ }^{37}$ & 2016 & 51 & $\begin{array}{l}\text { Primary induction failure, } \\
\text { refractory relapse }\end{array}$ & HLA-haploidentical & $\begin{array}{l}\text { Nonmyeloablative and high- } \\
\text { dose chemotherapy based }\end{array}$ & $53(1.5)$ & $44(1.5)$ \\
\hline Mohty et al. ${ }^{26}$ & 2016 & 24 & Primary induction failure & Related and unrelated & $\begin{array}{l}\text { CLO-based chemotherapy } \\
\text { followed by RIC }\end{array}$ & $38(2)$ & $29(2)$ \\
\hline $\begin{array}{l}\text { Pfrepper } \\
\text { et al. }{ }^{25}\end{array}$ & 2016 & 44 & $\begin{array}{l}\text { Primary induction failure and } \\
\text { refractory relapse }\end{array}$ & Related and unrelated & FLAMSA followed by RIC & $15(3)$ & $12(3)$ \\
\hline
\end{tabular}

Abbreviations: $\mathrm{BU}=$ busulfan; $\mathrm{CLO}=$ clofarabine; $\mathrm{DFS}=$ disease-free survival; FLAMSA = fludarabine, cytarabine and amsacrine; $\mathrm{HCT}=$ hematopoietic cell transplantation; OS = overall survival; RIC = reduced-intensity conditioning. Studies including patients with other hematological malignancies and disease stages were only included if outcomes were reported separately on patients with refractory or relapsed AML.

HLA-identical sibling donors. Although the conditioning regimen (high-dose busulfan vs TBI in combination with cyclophosphamide) did not seem to have a statistically significant impact on outcomes, the large size of the data set allowed for a multivariate analysis to identify risk factors associated with improved outcomes. In this data set, the 2-year overall and disease-free survivals (OS and DFS, respectively) in primary induction failure AML patients who received TBI-based conditioning were $39.7 \%$ and $35.2 \%$, respectively, whereas in those who received busulfanbased conditioning, $35.3 \%$ and $28.1 \%$, respectively. Posttransplant relapse rates were similar in both groups $(48.2 \%$ and $49.0 \%$, respectively). Interestingly, in this study, the presence of chronic GVHD did not seem to have an impact on post-transplant relapse rates in a time-dependent analysis.

Craddock et al..$^{20}$ analyzed the role of unrelated donor HCT in 168 patients with primary refractory $A M L$, also using EBMT Registry data. The majority of patients $(n=132)$ received myeloablative conditioning regimens, including 83 patients who underwent TBI-based conditioning. The 5-year OS for the whole cohort in this study was only $22 \%$. It is important to note that patients underwent HCT between 1994 and 2006; supportive care has improved considerably since that time. In multivariate analysis, fewer than three courses of chemotherapy, pretransplant marrow blasts fewer than the median blast percentage (38.5\%) and recipient CMV seropositivity were associated with improved OS. Based on this information, a score system was developed, and a good prognostic group (with no adverse prognostic factors) could be identified, who had a 5-year OS of $44 \pm 11 \%$. In contrast, patients with all three adverse prognostic factors present had a $0 \%$ long-term survival.

Although there is no consensus on the conditioning regimen to be used in this patient population, the majority of retrospective analyses included patients who received high-dose preparative regimens, making this treatment modality available only to younger, medically fit patients with refractory disease. One exception is the reduced-intensity conditioning regimen described by Oran et al., ${ }^{21}$ consisting of fludarabine and melphalan. Although the original communication describing this approach does include variable doses of melphalan, it is clear that the use of this regimen followed by administration of an HLA-matched related or unrelated donor graft can result in long-term survival in some older and medically infirm patients who have refractory AML. This study by Oran et al. ${ }^{21}$ included a total of 112 patients with high-risk AML and myelodysplastic syndrome $(n=30)$, including 32 patients with primary refractory and 43 patients with relapsed disease. Estimated 2-year OS was $40 \%$ in patients not in CR but who were without circulating blasts, and was $23 \%$ for those with active disease and circulating blasts.

In a more recent report from the MD Anderson Cancer Center, Jabbour et al. $^{22}$ compared outcomes of 28 primary refractory AML patients who underwent an allogeneic HCT as initial salvage to 149 patients with primary refractory AML who received salvage chemotherapy alone. The 28 patients received grafts from: an HLA-matched sibling, $n=18$; an HLA-matched unrelated donor, 
$n=7$; or an HLA-haploidentical related donor, $n=3$. All patients received high-dose cytarabine-based induction, and allotransplant patients received mostly fludarabine-based conditioning regimens (in combination with busulfan, $n=9$; melphalan, $n=7$ or other). The 3-year OS was 39\% for patients undergoing allogeneic HCT, vs only $2 \%$, for patients receiving salvage chemotherapy $(P<0.001)$. In a repeat, multivariate analysis, including 15 patients with refractory $A M L$ who received a subsequent (that is, delayed) allotransplant, allogeneic HCT, as initial salvage therapy, was the most significant predictor of improved DFS and OS.

A slightly different approach, using sequential combination chemotherapy immediately followed by an allotransplant with reduced-intensity conditioning, was introduced by Schmid et al. ${ }^{23}$ This strategy was subsequently adopted by several centers in Germany for the treatment of refractory and relapsed AML. ${ }^{24,25}$ The regimen consisted of fludarabine, cytarabine and amsacrine, followed after 3 days of rest and then by a 4-Gy TBI, cyclophosphamide and ATG-based reduced-intensity conditioning and allotransplant from related or unrelated donors. In the original study by Schmid et al., ${ }^{23}$ patients who did not develop GVHD by post-transplant day +120 received a prophylactic donor lymphocyte infusion (DLI). The study included patients with primary induction failure $(n=37)$ and early $(n=53)$, refractory $(n=8)$ or second $(n=5)$ relapse. The 2- and 4-year OS for the whole cohort was $40 \%$ and $32 \%$, respectively. However, patients with primary induction failure had a 2-year OS of $62.5 \%$; OS improved to $87 \%$ in the 17 patients who received prophylactic DLI, representing a remarkable clinical outcome in this challenging patient population.

A similar, sequential approach was recently reported by Mohty et al. ${ }^{26}$ In this study, 24 patients with primary refractory AML were treated with a sequential regimen consisting of clofarabine and cytarabine, followed by a 3-day rest, and then an allogeneic HCT utilizing a reduced-intensity conditioning regimen combining cyclophosphamide, busulfan (for 2 days) and antithymocyte globulin for 2 days. Patients in CR on posttransplant day +120 received prophylactic DLI. The 1 - and 2 -year leukemia-free survival was $46 \%$ and $29 \%$, respectively.

A recent analysis by Ferguson et $a l^{27}$ analyzed the effect of utilizing different definitions of primary induction failure on outcomes, in an attempt to identify patients with genuinely refractory AML earlier during their treatment courses. In this retrospective analysis, the authors included 8907 patients with non-promyelocytic $\mathrm{AML}$, treated with intensive chemotherapy regimens on various clinical trials. Outcomes of patients with refractory disease defined by differing criteria were examined. These criteria included failure to achieve CR after one cycle of induction chemotherapy (RES), less than a $50 \%$ reduction in blast numbers with $>15 \%$ residual blasts after one cycle of induction (REF1) and failure to achieve CR after two courses of induction chemotherapy (REF2). They found that 5-year OS was decreased in patients fulfilling any criteria for refractory disease compared with patients achieving CR after one cycle of chemotherapy: $9 \%$ and $8 \%$ in patients with REF1 and REF2, respectively, vs $40 \%$. They also found that allogeneic HCT improved OS in both REF1 and REF2 cohorts, and concluded that using the REF1 criteria allowed early identification of patients whose outcome after one course of induction therapy was very poor.

\section{UNTREATED AND REFRACTORY RELAPSE}

Owing mostly to logistic reasons such as a lack of immediately available donors or access to a transplant center, few studies have explored the role of allogeneic HCT in patients with untreated relapse. An earlier, but relatively large study was reported by Clift et al. $^{28}$ from the Fred Hutchinson Cancer Research Center. This investigation included 126 patients with AML who, between 1974 and 1990, underwent allogeneic HCT using HLA-identical sibling donor grafts during untreated first relapse. The 5-year DFS was $23 \%$. It is important to note, however, that while there was considerable variation in both the conditioning and GVHD prophylaxis regimens (in fact, 4 patients did not receive any GVHD prophylaxis), the majority of patients $(n=71)$ received a high-dose TBI-based conditioning of $15.75 \mathrm{~Gy}$, which previously was shown to reduce relapse rates, whereas increasing transplant-related deaths. ${ }^{29,30}$

A similar, 29\% 4-year DFS was reported by Brown et al., ${ }^{31}$ in 40 patients with $A M L$ in untreated first relapse undergoing HLA-matched or HLA-mismatched $(n=1)$ sibling HCT; conditioning included high-dose etoposide, cyclophosphamide and TBI (10 Gy). In this study, the pretransplant marrow blast content did not appear to impact post-transplant relapse risk.

Both of the above studies observed that patients who developed grade $\geqslant 2$ GVHD had improved DFS and a decreased risk of relapse.

The above data raise the question whether patients with AML in first untreated relapse should undergo allogeneic HCT as initial salvage therapy or should receive reinduction first. Although there are no data to strongly support either option, a theoretical calculation by Appelbaum et al. ${ }^{32}$ depicted in Figure 1 suggests that perhaps there would be a benefit for allogeneic HCT in this situation. This is, in part, due to the approximately $15-20 \%$ early death rate associated with reinduction attempts. In addition, in patients not achieving second $C R$ after reinduction (that is, in those patients with refractory relapsed $\mathrm{AML}$ ), cure rates associated with allogeneic HCT are considerably lower than in those with untreated first relapse. Needless to say, this calculation is based on reports of transplants performed in the 1980s and 1990s. The substantial improvements in HLA-typing, donor availability, conditioning regimens and supportive care certainly would merit further studying this question in the context of a clinical trial.

In most retrospective analyses, AML patients in refractory relapse are usually grouped together with those having primary induction failure or with patients in untreated relapse. However, patients with AML in refractory relapse seem to have a distinctly worse prognosis, especially when applying the more stringent definition of having failed the most recent reinduction therapy attempt to define refractory relapse. Earlier publications from the Fred Hutchinson Cancer Research Center in Seattle reported a $10 \%$ and $7 \%$ 3-5 year DFS after HLA-identical sibling and HLA-matched unrelated donors, respectively, using high-dose cyclophosphamide and TBI-based regimens. ${ }^{33,34}$ In a more recent study, Nagler et al. ${ }^{18}$ observed slightly improved outcomes using

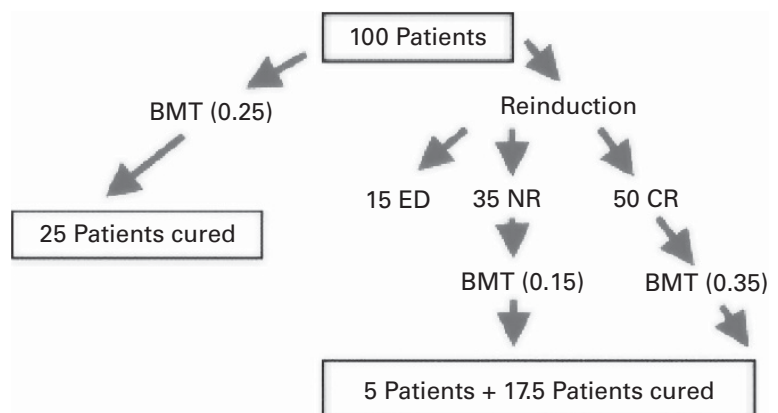

Figure 1. Should patients with $A M L$ in first untreated relapse be reinduced prior to bone marrow transplant? A theoretical calculation can be performed to determine the percentage of patients who will survive transplant without or with attempted reinduction. BMT, bone marrow transplantation; ED, early death; NR, not achieved second remission. Reproduced, with permission, from Appelbaum et al. ${ }^{32}$ A full color version of this figure is available at the Bone Marrow Transplantation journal online. 
a multivariate analysis in 852 patients with refractory $A M L$ undergoing allogeneic HCT from an HLA-identical sibling or an unrelated donor. They found that the risk of relapse was significantly higher for patients after first or second relapse when compared to those with primary refractory disease. The 2-year DFS in this report was approximately $24 \%$ and $15 \%$, respectively, for patients in first and second refractory relapse.

\section{PROGNOSTIC SCORE SYSTEMS}

To aid clinical decision making, several attempts were made to identify factors associated with improved outcomes in patients with primary refractory or relapsed AML. A multivariate analysis from the MD Anderson Cancer Center, including 135 patients with refractory AML and myelodysplastic syndrome $(n=24)$ who underwent allogeneic HCT from related or unrelated donors, showed that Karnofsky performance status, peripheral blast content and tacrolimus exposure (defined by the area under the receiver operating characteristic curve (AUC) of tacrolimus levels during the first 11 days) were predictive of survival. ${ }^{35}$ Of note, the authors emphasize that tacrolimus exposure (AUC) over the first 11 days had a log quadratic relationship with the log hazard of death; the death rate initially decreased with AUC, but then increased at higher levels. Based on their data, the authors suggested maintaining optimal tacrolimus exposure during the first 15 days after transplantation, with the optimal target range of serum tacrolimus levels during these days being between 7 and $9 \mathrm{ng} / \mathrm{dL}$

A larger, more recent report from the Center for International Blood and Marrow Transplant Research (CIBMTR) analyzed 1673 patients with AML with primary induction failure, in first untreated or refractory relapse, and in subsequent relapse undergoing allogeneic HCT following a high-dose busulfan- or TBI-based conditioning regimen. ${ }^{36}$ Patients undergoing syngeneic or cord blood transplantations were excluded. Overall survival for the whole cohort of AML patients at 3 years was $19 \%$. Multivariate analysis at 3 years showed worse OS for patients in first relapse after a short ( $<6$ months) initial CR but better after a longer ( $>6$ months) initial $C R$, when compared to those with primary refractory AML. For patients in first untreated or refractory relapse, the 3-year OS was similar. The presence of circulating blasts, a mismatched unrelated donor, a related donor other than an HLAmatched sibling, a Karnofsky score $<90 \%$ and poor-risk cytogenetics were identified as additional adverse risk factors. By using these five risk factors, a prognostic score system (the 'Duval Score') was developed, as shown in Table 2. As depicted in Figure 2, patients with a score of 0 had a 3 -year OS of $42 \%$, while correspondingly, 3-year OS in patients with a score of $\geqslant 3$ was only $6 \%$.

\section{ALTERNATIVE DONOR SOURCES}

Limited HCT data have been published using alternative donor sources, such as HLA-haploidentical donors or umbilical cord blood. A relatively large study from Jaiswal et al. ${ }^{37}$ reported encouraging results using HLA-haploidentical grafts after incremental optimization of the conditioning regimen and the use of post-transplant DLI in AML patients not in remission. In this study, 41 patients received myeloablative conditioning, and 21 also received G-CSF-mobilized DLI on days 21, 35 and 60 after HCT. Interestingly, the 18-month incidence of disease progression and DFS were $66 \%$ and $25 \%$, respectively, in patients who did not receive DLI, compared with $21 \%$ and $62 \%$, respectively, in those who did. Use of a natural killer cell alloreactive donor was associated with a lower incidence of disease progression only in patients who did not receive DLI. The authors concluded that a myeloablative conditioning regimen and early administration of
Table 2. Scoring system for post-transplant outcome in AML

\begin{tabular}{|c|c|c|}
\hline Risk factor & Score & $\begin{array}{l}\text { No. of } \\
\text { patients }\end{array}$ \\
\hline \multicolumn{3}{|l|}{ Disease group } \\
\hline PIF or duration of first $C R>6$ months & 0 & 763 \\
\hline Duration of first $C R<6$ months & 1 & 374 \\
\hline \multicolumn{3}{|l|}{ Cytogenetics prior to $\mathrm{HCT}$} \\
\hline Good or intermediate & 0 & 901 \\
\hline Poor & 1 & 236 \\
\hline \multicolumn{3}{|l|}{ HLA match group } \\
\hline $\begin{array}{l}\text { HLA identical sibling or well matched or partially } \\
\text { matched unrelated }\end{array}$ & 0 & 900 \\
\hline Mismatched unrelated & 1 & 156 \\
\hline Related other than HLA identical sibling & 2 & 81 \\
\hline \multicolumn{3}{|l|}{ Circulating blasts } \\
\hline Absent & 0 & 503 \\
\hline Present & 1 & 634 \\
\hline \multicolumn{3}{|l|}{ Karnofsky or Lansky score } \\
\hline $90-100$ & 0 & 604 \\
\hline$<90$ & 1 & 533 \\
\hline
\end{tabular}

Abbreviations: $\mathrm{HCT}=$ hematopoietic cell transplantation; $\mathrm{PIF}=$ primary induction failure. Overall score is defined as the sum of the scores for each risk factor. Four risk groups were defined as follows: score of $0,1,2$, and $\geqslant 3$. Reproduced, with permission, from Duval et al. ${ }^{36}$

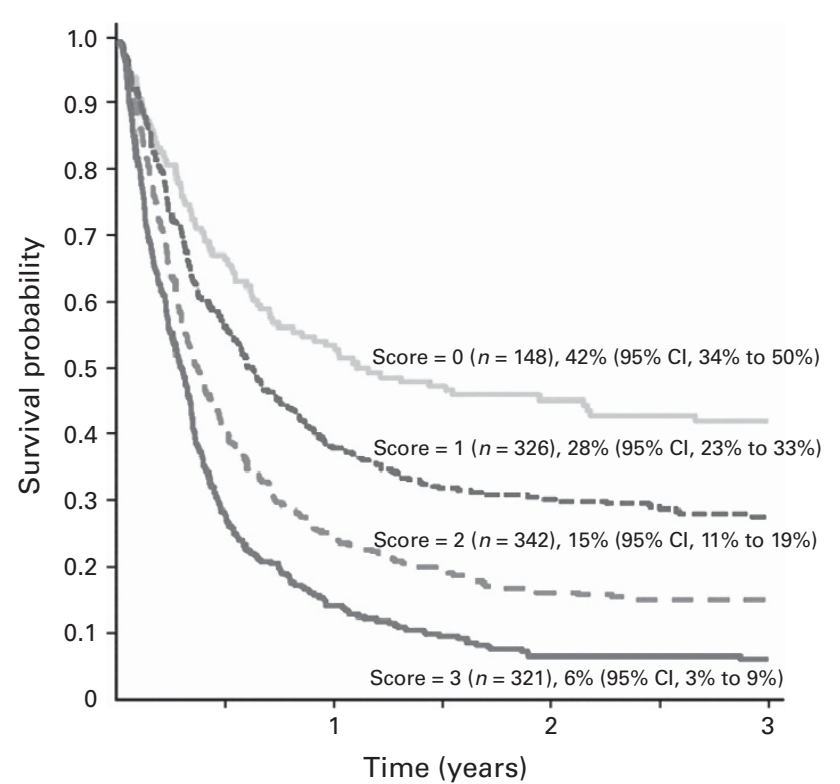

Figure 2. Probability of OS after transplantation for $A M L$ in relapse or primary induction failure according to risk score. The 3-year survival rates and $95 \%$ confidence intervals $(\mathrm{Cls})$ are indicated. Reproduced, with permission, from Duval et al. ${ }^{36} \mathrm{~A}$ full color version of this figure is available at the Bone Marrow Transplantation journal online.

G-CSF-mobilized DLI were factors associated with a decreased incidence of disease progression and improved DFS.

Similarly, only limited data have been published about successful umbilical cord blood transplantation (UCBT) in the setting of refractory AML to date, including anecdotal reports. ${ }^{38}$ A larger study by Laughlin et al. ${ }^{39}$ compared outcomes after UCBT and unrelated donors in adult patients with acute leukemia. 
Although this analysis included a substantial number of patients with advanced disease undergoing UCBT $(n=64)$, including relapsed leukemia and primary induction failure, and while the overall outcomes were encouraging for the whole cohort, patients with relapsed and refractory AML were lumped together with patients in other disease stages and outcomes were not reported separately. Similarly, Ooi et al. ${ }^{40}$ reported on 18 patients with AML who underwent UCBT at a single institution, including six patients in relapse and two patients with primary induction failure. Although the whole cohort had an impressive, $76.6 \%$ DFS at 2 years, outcomes of patients with AML not in remission at the time of transplant were not reported separately. Based on individual outcome reports, all four patients in this small cohort who died had relapsed or primary refractory $A M L$ at the time of UCBT. Overall, these reports suggest a promising role for UCBT in patients with refractory or relapsed $A M L$, especially in patients who do not have suitable related or unrelated donors readily available. Prospective trials will be needed to further define the role of UCBT in this scenario, to exploit its unique characteristics of reduced time required for accessing the graft and possibly improved disease control.

\section{NOVEL APPROACHES}

The above described retrospective analyses included mostly younger patients who were able to tolerate high-dose conditioning regimens. Not only to improve outcomes in this population but also to make this treatment modality available to older and medically infirm patients with refractory or relapsed $A M L$, novel strategies are needed. One such approach is the incorporation of monoclonal antibodies conjugated either to a cytotoxic agent or to a radioactive isotope. This design facilitates a targeted delivery of the antileukemic treatment to the leukemic cells, thereby improving disease control without imposing excessive toxicity to healthy organs. To achieve a favorable biodistribution of a monoclonal antibody conjugated to a cytotoxin or a radioisotope, an ideal antigen would be expressed homogeneously on the tumor cell surface but would lack expression on normal cells. CD33 and CD45 (common leukocyte antigen) are attractive lineage-specific hematopoietic antigens for this purpose and have been successfully developed in the allogeneic HCT setting. ${ }^{41,42}$

Extensive experience already has been published using iodine131 ( ${ }^{131} \mathrm{I}$ )-labeled anti-CD45 antibody ( ${ }^{131} \mathrm{I}-\mathrm{BC} 8$; lomab-B; Actinium Pharmaceuticals, Inc., Edison, NJ, USA) to deliver targeted hematopoietic irradiation to the marrow, spleen and lymph nodes for improved leukemia control without unacceptably high regimen-related toxicity. ${ }^{43,44}$ The CD45 antigen is expressed on the surface of virtually all hematopoietic cells, except mature red cells and platelets. In addition, CD45 expression has been detected in $85-90 \%$ of AML. Further, the antigen does not internalize after antibody binding.

In a phase 1 study, elderly patients with advanced AML or myelodysplastic syndrome were treated with escalating doses of ${ }^{131}$ I-labeled anti-CD45 antibody, in combination with fludarabine and $2 \mathrm{~Gy} \mathrm{TBI}$ as conditioning, followed by allogeneic HCT, as shown in Figure $3 .{ }^{45}$ This study enrolled 58 AML patients, 39 of whom had untreated or refractory relapse. The identified maximum tolerated dose of the ${ }^{131}$ I-labeled anti-CD45 antibody was $24 \mathrm{~Gy}$ administered to the liver and $48 \mathrm{~Gy}$ to the marrow. Within the difficult-to-treat subset of elderly patients with $A M L$ in untreated or refractory relapse, addition of the ${ }^{131}$ I-labeled antiCD45 antibody to a nonmyeloablative conditioning regimen resulted in a 1-year OS and DFS of 33.\%. The leading cause of treatment failure was relapse, the incidence of which was $50 \%$ at 1 year post HCT.

On June 29, 2016, Actinium Pharmaceuticals announced the initiation of a phase III clinical trial to compare efficacy of this approach to treatment with conventional chemotherapy in

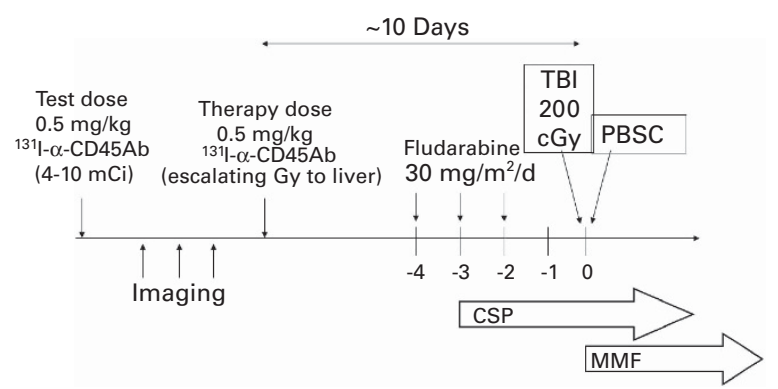

Figure 3. Treatment scheme of conditioning regimen incorporating ${ }^{131} \mathrm{I}$-anti-CD45 into a nonmyeloablative regimen as described by Pagel et al. ${ }^{45}$ CSP, cyclosporine A; MMF, mycophenolate mofetil.

patients with relapsed or refractory AML (Study of lomab-B Prior to HCT vs Conventional Care in Older Subjects With Active, Relapsed or Refractory AML; SIERRA; ClinicalTrials.gov Identifier: NCT02665065).

The use of the ${ }^{131}$ I-labeled anti-CD45 antibody in the HLA-haploidentical setting is currently being explored in clinical trials for patients lacking HLA-matched related or unrelated donors (ClinicalTrials.gov Identifier: NCT00589316).

Future directions include conjugating the anti-CD45 antibody with alternative radioisotopes including ${ }^{90} \mathrm{Y}$, which is a pure $\beta$-emitter lacking the medium-energy gamma component of ${ }^{131} \mathrm{I}$, eliminating the need for radiation isolation of patients treated (ClinicalTrials.gov Identifier: NCT01300572). Alpha emitters are currently being tested in preclinical trials.

Another approach that has been extensively explored is the targeting of the CD33 antigen. Like CD45, normal tissue expression of CD33 is largely restricted to hematopoietic cells. Furthermore, this epitope is consistently expressed on the leukemic cells in $>90 \%$ of AML cases, regardless of patient age or AML mutational profile. Initial trials incorporating ${ }^{131}$ I-labeled anti-CD33 antibody (clone p67), however, showed limited success in eradicating leukemic cells, likely owing to the relatively rapid clearance of the ${ }^{131}$ I-labeled anti-CD33 antibody, which was thought to result from rapid internalization of the antibodyantigen complex and the release of ${ }^{131}$ I from the marrow space. ${ }^{41}$ Investigators at the Memorial Sloan Kettering Cancer Center used a slightly different ${ }^{131}$ I-labeled murine monoclonal antibody against CD33, designated as M195. ${ }^{46,47}$ Early-phase trials testing a humanized version of this antibody in a 17 patient cohort comprised of patients with primary refractory disease or untreated or refractory relapse. Allogeneic HCT used grafts from HLAidentical or one antigen mismatched related donors. The administration of the ${ }^{131}$ I-labeled anti-CD33 antibody was followed by a high-dose conditioning regimen consisting of busulfan and cyclophosphamide. The regimen was well tolerated and resulted in a median survival of 5.7 months; 3 of the 17 patients remained alive at $59+, 87+$ and $90+$ months posttransplant at the time of publication. ${ }^{48}$ However, owing to limitations associated with these radiolabeled antibodies, such as decreased antibody-binding affinity to CD33 after radioiodination and the required radiation isolation, this approach did not advance into more widespread use.

A more recent, promising attempt to target CD33 in the setting of allogeneic HCT is the incorporation SGN-CD33A (vadastuximab talirine; Seattle Genetics, Inc., Bothell, WA, USA) into the conditioning regimen of allogeneic HCT. SGN-CD33A is an antibody-drug conjugate composed of an engineered anti-CD33 monoclonal antibody conjugated to a highly potent DNA crosslinking agent; the latter is released upon internalization of the conjugate. Initial trials showed promising activity in patients with relapsed or refractory $\mathrm{AML}$, who subsequently underwent allogeneic $\mathrm{HCT}^{49}$ An ongoing, phase $1-2$ study is exploring the 
role of vadastuximab talirine in the setting of allogeneic HCT, both as part of the conditioning regimen as well as in the posttransplant maintenance setting for patients with relapsed or refractory AML.

\section{CONCLUSIONS}

In summary, retrospective data show that allogeneic $\mathrm{HCT}$ performed in patients with $\mathrm{AML}$ with primary refractory disease or in relapse (untreated or refractory) can result in longterm DFS in a subset of patients. There is no consensus on the conditioning regimen, but retrospective studies mostly included younger patients who received high-dose chemotherapy or TBI-based regimens. Also, likely owing to the perceived urgency of these situations and the time required to perform an unrelated donor search, most published reports include patients with HLA-identical sibling donors. This bias may change, as efficiency of HLA-typing and unrelated donor search are improving. Further, the emergence of other alternative donor graft sources such as umbilical cord blood and haploidentical grafts theoretically could be successfully utilized in this scenario. Furthermore, in the appropriate setting, when several donors are available, selecting donors with activating KIR genes could contribute to disease control. $^{50}$

Especially intriguing is the recent publication by Jaiswal et al. ${ }^{37}$ showing success with HLA-haploidentical related donors, who immediately could be accessible when only limited time is available to identify a suitable donor. An additional measure to improve the efficacy of a donor search is early HLA-typing of AML patients and their family members, possibly at the time of diagnosis. Other means to enhance the process include exploring donor options via a preliminary unrelated donor and umbilical cord blood unit searches while patients are receiving induction therapy and information on their risk stratification is emerging. Furthermore, when more than one donor is available, the selection of those persons who express activating KIR genes could contribute to better disease control, so early KIR-typing of suitable donors could also accelerate the donor selection process.

The accumulated retrospective data also show that, while allogeneic HCT might provide the best chance for cure in this population, it is still only successful in about $20-40 \%$ of patients with primary refractory or relapsed AML. The leading cause of treatment failure is almost uniformly disease progression. Although recent data from Scott et al..$^{51}$ (Bone Marrow Transplant Clinical Trials Network 0901, 'MAVERICK' trial) suggest an important role of dose intensity in disease control, past experiences also demonstrated that, while higher doses of $\mathrm{TBI}$ do result in reduced relapse risk, this choice came at the price of increased, often fatal gastrointestinal, hepatic and pulmonary toxicities, secondary malignancies and impaired growth and development in children. ${ }^{29,30}$ Additional, novel interventions are needed to improve disease control without excessive additional toxicity. One such approach could be the incorporation of targeted therapy into the conditioning regimen. The use of ${ }^{131}$ I-labeled anti-CD45 antibody in combination with a nonmyeloablative conditioning regimen has been associated with considerable success for the treatment of older refractory and relapsed $\mathrm{AML}$ patients. Trials incorporating SGN-CD33A (vadastuximab talirine) into the conditioning regimen of allogeneic HCT are currently ongoing.

Another approach could be the use of maintenance therapy early after allogeneic HCT to provide disease control while graft-versus-leukemia (GVL) effects can fully develop. Low-dose azacitidine has been extensively used as maintenance therapy after allogeneic HCT for high-risk AML. ${ }^{52,53}$ The emergence of novel therapies targeting specific mutations (such as FLT3-ITD, IDH1 and IDH2 and so on) could provide viable, personalized options for maintenance therapy after allotransplant. Early post- transplant DLI both in the HLA-matched and HLA-haploidentical setting was also shown to improve disease control that translated into improved DFS and OS.

In conclusion, allogeneic HCT should be considered in AML patients with primary refractory disease or in those with untreated or refractory relapse, preferably in the context of a clinical trial testing such novel approaches. Early HLA-typing of patients and family members and early involvement of the blood and marrow transplant team in the care of newly diagnosed AML patients could facilitate identification of a suitable donor. These maneuvers potentially can overcome some of the barriers to performing allogeneic HCT in patients whose disease does not respond to induction therapy or to salvage therapy.

\section{CONFLICT OF INTEREST}

Boglarka Gyurkocza: consultant for Actinium Pharmaceuticals. Hillard M Lazarus: Senior Editor for Bone Marrow Transplantation and consultant for Actinium Pharmaceuticals and Seattle Genetics. Sergio Giralt: research funding from Celgene, Sanofi and Takeda-Millenium; consultant for Actinium Pharmaceuticals; and membership on an Advisory Committee for Amgen, Celgene, JAZZ, Johnson \& Johnson, Novartis, Sanofi, Seattle Genetics and Takeda.

\section{ACKNOWLEDGEMENTS}

This work was supported by grants from the Hematopoietic Biorepository Core of the Case Comprehensive Cancer Center (P30CA043703) and NIH U01CA180853 and U01CA180820.

\section{REFERENCES}

1 Cheson BD, Bennett JM, Kopecky KJ, Buchner T, Willman CL, Estey EH et al. Revised recommendations of the International Working Group for Diagnosis, Standardization of Response Criteria, Treatment Outcomes, and Reporting Standards for Therapeutic Trials in Acute Myeloid Leukemia. J Clin Oncol 2003; 21: 4642-4649.

2 Fernandez HF, Sun Z, Yao X, Litzow MR, Luger SM, Paietta EM et al. Anthracycline dose intensification in acute myeloid leukemia. N Engl J Med 2009; 361: 1249-1259.

3 Gardin C, Turlure P, Fagot T, Thomas X, Terre C, Contentin N et al. Postremission treatment of elderly patients with acute myeloid leukemia in first complete remission after intensive induction chemotherapy: results of the multicenter randomized Acute Leukemia French Association (ALFA) 9803 trial. Blood 2007; 109: 5129-5135.

4 Lowenberg B, Ossenkoppele GJ, van Putten W, Schouten HC, Graux C, Ferrant A et al. High-dose daunorubicin in older patients with acute myeloid leukemia. N Engl J Med 2009; 361: 1235-1248.

5 Kantarjian HM, Erba HP, Claxton D, Arellano M, Lyons RM, Kovascovics T et al. Phase II study of clofarabine monotherapy in previously untreated older adults with acute myeloid leukemia and unfavorable prognostic factors. J Clin Oncol 2010; 28: 549-555.

6 Estey EH. Treatment of relapsed and refractory acute myelogenous leukemia. Leukemia 2000; 14: 476-479.

7 NCCN. Acute Myeloid Leukemia NCCN Guidelines. NCCN Clin Pract Guidelines Oncol 2016; 2.2016: 1-100.

8 Martin MG, Augustin KM, Uy GL, Welch JS, Hladnik L, Goyal S et al. Salvage therapy for acute myeloid leukemia with fludarabine, cytarabine, and idarubicin with or without gemtuzumab ozogamicin and with concurrent or sequential G-CSF. Am J Hematol 2009; 84: 733-737.

9 Wierzbowska A, Robak T, Pluta A, Wawrzyniak E, Cebula B, Holowiecki J et al. Cladribine combined with high doses of arabinoside cytosine, mitoxantrone, and G-CSF (CLAG-M) is a highly effective salvage regimen in patients with refractory and relapsed acute myeloid leukemia of the poor risk: a final report of the Polish Adult Leukemia Group. Eur J Haematol 2008; 80: 115-126.

10 Montillo M, Mirto S, Petti MC, Latagliata R, Magrin S, Pinto A et al. Fludarabine, cytarabine, and G-CSF (FLAG) for the treatment of poor risk acute myeloid leukemia. Am J Hematol 1998; 58: 105-109.

11 Parker JE, Pagliuca A, Mijovic A, Cullis JO, Czepulkowski B, Rassam SM et al. Fludarabine, cytarabine, G-CSF and idarubicin (FLAG-IDA) for the treatment of poor-risk myelodysplastic syndromes and acute myeloid leukaemia. $\mathrm{Br} J$ Haematol 1997; 99: 939-944.

12 Amadori S, Arcese W, Isacchi G, Meloni G, Petti MC, Monarca B et al. Mitoxantrone, etoposide, and intermediate-dose cytarabine: an effective and tolerable regimen 
for the treatment of refractory acute myeloid leukemia. J Clin Oncol 1991; 9: 1210-1214.

13 Becker PS, Kantarjian HM, Appelbaum FR, Petersdorf SH, Storer B, Pierce S et al. Clofarabine with high dose cytarabine and granulocyte colony-stimulating factor (G-CSF) priming for relapsed and refractory acute myeloid leukaemia. $\mathrm{Br} \mathrm{J}$ Haematol 2011; 155: 182-189.

14 Faderl S, Ferrajoli A, Wierda W, Huang X, Verstovsek S, Ravandi F et al. Clofarabine combinations as acute myeloid leukemia salvage therapy. Cancer 2008; 113: 2090-2096.

15 Estey E, Kornblau S, Pierce S, Kantarjian H, Beran M, Keating M. A stratification system for evaluating and selecting therapies in patients with relapsed or primary refractory acute myelogenous leukemia. Blood 1996; 88: 756.

16 Biggs JC, Horowitz MM, Gale RP, Ash RC, Atkinson K, Helbig W et al. Bone marrow transplants may cure patients with acute leukemia never achieving remission with chemotherapy. Blood 1992; 80: 1090-1093.

17 Fung HC, Stein A, Slovak M, O'Donnell MR, Snyder DS, Cohen S et al. A long-term follow-up report on allogeneic stem cell transplantation for patients with primary refractory acute myelogenous leukemia: impact of cytogenetic characteristics on transplantation outcome. Biol Blood Marrow Transplant 2003; 9: 766-771.

18 Nagler A, Savani BN, Labopin M, Polge E, Passweg J, Finke J et al. Outcomes after use of two standard ablative regimens in patients with refractory acute myeloid leukaemia: a retrospective, multicentre, registry analysis. Lancet Haematol 2015; 2: e384-e392.

19 Ravandi F. Primary refractory acute myeloid leukaemia-in search of better definitions and therapies. Br J Haematol 2011; 155: 413-419.

20 Craddock C, Labopin M, Pillai S, Finke J, Bunjes D, Greinix H et al. Factors predicting outcome after unrelated donor stem cell transplantation in primary refractory acute myeloid leukaemia. Leukemia 2011; 25: 808-813.

21 Oran B, Giralt S, Saliba R, Hosing C, Popat U, Khouri I et al. Allogeneic hematopoietic stem cell transplantation for the treatment of high-risk acute myelogenous leukemia and myelodysplastic syndrome using reduced-intensity conditioning with fludarabine and melphalan. Biol Blood Marrow Transplant 2007; 13: 454-462.

22 Jabbour E, Daver N, Champlin R, Mathisen M, Oran B, Ciurea S et al. Allogeneic stem cell transplantation as initial salvage for patients with acute myeloid leukemia refractory to high-dose cytarabine-based induction chemotherapy. Am J Hematol 2014; 89: 395-398.

23 Schmid C, Schleuning M, Schwerdtfeger R, Hertenstein B, Mischak-Weissinger E, Bunjes $D$ et al. Long-term survival in refractory acute myeloid leukemia after sequential treatment with chemotherapy and reduced-intensity conditioning for allogeneic stem cell transplantation. Blood 2006; 108: 1092-1099.

24 Schneidawind D, Federmann B, Faul C, Vogel W, Kanz L, Bethge WA. Allogeneic hematopoietic cell transplantation with reduced-intensity conditioning following FLAMSA for primary refractory or relapsed acute myeloid leukemia. Ann Hematol 2013; 92: 1389-1395.

25 Pfrepper C, Klink A, Behre G, Schenk T, Franke GN, Jentzsch M et al. Risk factors for outcome in refractory acute myeloid leukemia patients treated with a combination of fludarabine, cytarabine, and amsacrine followed by a reduced-intensity conditioning and allogeneic stem cell transplantation. J Cancer Res Clin Oncol 2016; 142: 317-324.

26 Mohty M, Malard F, Blaise D, Milpied N, Socie G, Huynh A et al. Sequential regimen of clofarabine, cytosine arabinoside and reduced intensity transplantation for primary refractory acute myeloid leukemia. Haematologica 2016; 102: 184-191.

27 Ferguson P, Hills RK, Grech A, Betteridge S, Kjeldsen L, Dennis M et al. An operational definition of primary refractory acute myeloid leukemia allowing early identification of patients who may benefit from allogeneic stem cell transplantation. Haematologica 2016; 101: 1351-1358.

28 Clift RA, Buckner CD, Appelbaum FR, Schoch G, Petersen FB, Bensinger WI et al. Allogeneic marrow transplantation during untreated first relapse of acute myeloid leukemia. J Clin Oncol 1992; 10: 1723-1729.

29 Clift RA, Buckner CD, Appelbaum FR, Bearman SI, Petersen FB, Fisher LD et al. Allogeneic marrow transplantation in patients with acute myeloid leukemia in first remission: a randomized trial of two irradiation regimens. Blood 1990; 76: 1867-1871.

30 Clift RA, Buckner CD, Appelbaum FR, Sullivan KM, Storb R, Thomas ED. Long-term follow-Up of a randomized trial of two irradiation regimens for patients receiving allogeneic marrow transplants during first remission of acute myeloid leukemia. Blood 1998; 92: 1455-1456.

31 Brown RA, Wolff SN, Fay JW, Pineiro L, Collins RH Jr, Lynch JP et al. High-dose etoposide, cyclophosphamide, and total body irradiation with allogeneic bone marrow transplantation for patients with acute myeloid leukemia in untreated first relapse: a study by the North American Marrow Transplant Group. Blood 1995; 85: 1391-1395.
32 Appelbaum FR, Pearce SF. Hematopoietic cell transplantation in first complete remission versus early relapse. Best Pract Res Clin Haematol 2006; 19: 333-339.

33 Appelbaum FR, Clift RA, Buckner CD, Stewart P, Storb R, Sullivan KM et al. Allogeneic marrow transplantation for acute nonlymphoblastic leukemia after first relapse. Blood 1983; 61: 949-953.

34 Sierra J, Storer B, Hansen JA, Martin PJ, Petersdorf EW, Woolfrey A et al. Unrelated donor marrow transplantation for acute myeloid leukemia: an update of the Seattle experience. Bone Marrow Transplant 2000; 26: 397-404.

35 Wong R, Shahjahan M, Wang X, Thall PF, De Lima M, Khouri I et al. Prognostic factors for outcomes of patients with refractory or relapsed acute myelogenous leukemia or myelodysplastic syndromes undergoing allogeneic progenitor cell transplantation. Biol Blood Marrow Transplant 2005; 11: 108-114.

36 Duval M, Klein JP, He W, Cahn JY, Cairo M, Camitta BM et al. Hematopoietic stemcell transplantation for acute leukemia in relapse or primary induction failure. J Clin Oncol 2010; 28: 3730-3738.

37 Jaiswal SR, Zaman S, Chakrabarti A, Sen S, Mukherjee S, Bhargava S et al. Improved outcome of refractory/relapsed acute myeloid leukemia after posttransplantation cyclophosphamide-based haploidentical transplantation with myeloablative conditioning and early prophylactic granulocyte colonystimulating factor-mobilized donor lymphocyte infusions. Biol Blood Marrow Transplant 2016; 22: 1867-1873.

38 Lee SY, Kurita N, Maie K, Seki M, Yokoyama Y, Suzukawa K et al. Prolonged survival of a refractory acute myeloid leukemia patient after a third hematopoietic stem cell transplantation with umbilical cord blood following a second relapse. Case Rep Hematol 2014; 2014: 918708.

39 Laughlin MJ, Eapen M, Rubinstein P, Wagner JE, Zhang MJ, Champlin RE et al. Outcomes after transplantation of cord blood or bone marrow from unrelated donors in adults with leukemia. N Engl J Med 2004; 351: 2265-2275.

40 Ooi J, Iseki T, Takahashi S, Tomonari A, Takasugi K, Shimohakamada Y et al. Unrelated cord blood transplantation for adult patients with de novo acute myeloid leukemia. Blood 2004; 103: 489-491.

41 Appelbaum FR, Matthews DC, Eary JF, Badger CC, Kellogg M, Press OW et al. The use of radiolabeled anti-CD33 antibody to augment marrow irradiation prior to marrow transplantation for acute myelogenous leukemia. Transplantation 1992; 54: 829-833.

42 Jurcic JG, Caron PC, Nikula TK, Papadopoulos EB, Finn RD, Gansow OA et al. Radiolabeled anti-CD33 monoclonal antibody M195 for myeloid leukemias. Cancer Res 1995; 55: 5908s-5910s.

43 Matthews DC, Appelbaum FR, Eary JF, Fisher DR, Durack LD, Hui TE et al. Phase I study of (131)l-anti-CD45 antibody plus cyclophosphamide and total body irradiation for advanced acute leukemia and myelodysplastic syndrome. Blood 1999; 94: 1237-1247.

44 Pagel JM, Appelbaum FR, Eary JF, Rajendran J, Fisher DR, Gooley T et al. 1311-antiCD45 antibody plus busulfan and cyclophosphamide before allogeneic hematopoietic cell transplantation for treatment of acute myeloid leukemia in first remission. Blood 2006; 107: 2184-2191.

45 Pagel JM, Gooley TA, Rajendran J, Fisher DR, Wilson WA, Sandmaier BM et al. Allogeneic hematopoietic cell transplantation after conditioning with 131I-antiCD45 antibody plus fludarabine and low-dose total body irradiation for elderly patients with advanced acute myeloid leukemia or high-risk myelodysplastic syndrome. Blood 2009; 114: 5444-5453.

46 Caron PC, Schwartz MA, Co MS, Queen C, Finn RD, Graham MC et al. Murine and humanized constructs of monoclonal antibody M195 (anti-CD33) for the therapy of acute myelogenous leukemia. Cancer 1994; 73: 1049-1056.

47 Caron PC, Jurcic JG, Scott AM, Finn RD, Divgi CR, Graham MC et al. A phase 1B trial of humanized monoclonal antibody M195 (anti-CD33) in myeloid leukemia: specific targeting without immunogenicity. Blood 1994; 83: 1760-1768.

48 Burke JM, Caron PC, Papadopoulos EB, Divgi CR, Sgouros G, Panageas KS et al. Cytoreduction with iodine-131-anti-CD33 antibodies before bone marrow transplantation for advanced myeloid leukemias. Bone Marrow Transplant 2003; 32: 549-556.

49 Stein AS, Walter RB, Advani AS, Ho PA, Erba HB. SGN-CD33A (Vadastuximab Talirine) followed by allogeneic hematopoietic stem cell transplant (AlloHSCT) results in durable complete remissions (CRs) in patients with acute myeloid leukemia (AML). Biol Blood Marrow Transplant 2016; 22: S211-S212.

50 Venstrom JM, Pittari G, Gooley TA, Chewning JH, Spellman S, Haagenson M et al. HLA-C-dependent prevention of leukemia relapse by donor activating KIR2DS1. N Engl J Med 2012; 367: 805-816.

51 Scott BL, Pasquini MC, Logan B, Wu J, Devine S, Porter DL et al. Results of a phase III randomized, multi-center study of allogeneic stem cell transplantation after high versus reduced intensity conditioning in patients with myelodysplastic syndrome (MDS) or acute myeloid leukemia (AML): Blood and Marrow Transplant Clinical Trials Network (BMT CTN) 0901. Blood 2015; 126: LBA-8. 
52 de Lima M, Giralt S, Thall PF, de Padua Silva L, Jones RB, Komanduri $\mathrm{K}$ et al. Maintenance therapy with low-dose azacitidine after allogeneic hematopoietic stem cell transplantation for recurrent acute myelogenous leukemia or myelodysplastic syndrome: a dose and schedule finding study. Cancer 2010; 116: 5420-5431.
53 Craddock C, Jilani N, Siddique S, Yap C, Khan J, Nagra S et al. Tolerability and clinical activity of post-transplantation azacitidine in patients allografted for acute myeloid leukemia treated on the RICAZA Trial. Biol Blood Marrow Transplant 2016; 22: $385-390$ 